\title{
Assessment of Equipment Utilization and Maintenance Schedule at a Dental Institution in Bengaluru, India
}

\author{
${ }^{1}$ Vaibhav Gupta, ${ }^{2}$ Nitin Gupta, ${ }^{3}$ Gargi S Sarode, ${ }^{4}$ Sachin C Sarode, ${ }^{5}$ Shankargouda Patil
}

\begin{abstract}
Introduction: Quality of diagnostic and treatment care provided to patients largely depends on the availability of sophisticated medical equipment. Regular equipment maintenance helps in providing quality care and maintaining utilization coefficient (UC) of the medical equipment. Equipment utilization is the evaluation of medical equipment necessity, appropriateness, and efficiency of the use in diagnosing and treating a patient. If equipment shows UC of more than $50 \%$, it is said to be a good investment.
\end{abstract}

Objective: To assess UC of dental institution equipment along with their maintenance schedule to increase operational efficiency.

Materials and methods: An observational study was conducted at a 250 chaired dental institution in Bengaluru in 2015 to calculate the use coefficient of medical equipment. Maintenance schedule was also recorded for all the equipment. Necessary permissions were obtained before starting the study.

Results: Around $50 \%$ of these medical equipments were underutilized. Only four equipments had preventive maintenance schedule under which services usually provided every 4 months. Most of the equipment did not have any maintenance contract.

Conclusion: It should be an earnest endeavor of the management and users to optimize the equipment utilization to obtain maximum return on capital invested. In an era of cost-intensive medical care, every equipment being installed in health care institutions need to be fully and properly utilized.

Clinical Significance: Findings of this study will enable the administrators to ensure that the equipment is in proper working condition to provide optimal patient care.

Keywords: Annual maintenance contract, Comprehensive maintenance contract, Dental, Equipment, Maintenance, Use coefficient.

\footnotetext{
${ }^{1}$ Department of Public Health Dentistry, Faculty of Dental Science, Shree Guru Gobind Singh Tricentenary University Gurugram, Haryana, India

${ }^{2}$ Department of Public Health Dentistry, Dr. D.Y. Patil Vidyapeeth Pune, Maharashtra, India

${ }^{3,4}$ Department of Oral Pathology \& Microbiology, Dr. D.Y. Patil Vidyapeeth, Pune Maharashtra, India

${ }^{5}$ Department of Maxillofacial Surgery and Diagnostic Sciences College of Dentistry, Jazan University, Jazan, Kingdom of Saudi Arabia

Corresponding author: Sachin C Sarode, Department of Oral Pathology \& Microbiology, Dr. D.Y. Patil Vidyapeeth Pune, Maharashtra, India, Phone: +919922491465, e-mail: drsachinsarode@gmail.com/sachin.sarode@dpu.edu.in
}

How to cite this article: Gupta V, Gupta N, Sarode GS, Sarode SC, Patil S. Assessment of Equipment Utilization and Maintenance Schedule at a Dental Institution in Bengaluru, India. World J Dent 2017;8(2):104-108.

\section{Source of support: Nil}

Conflict of interest: None

\section{INTRODUCTION}

In the present health care scenario, increasing operational efficiency and reducing costs, while improving service provided to the patient, are a constant challenge. Advances in engineering and information technology, particularly during the last few decades, have revolutionized medical care. Medical equipment plays a very significant role in the health care delivery system. Alma-Ata Declaration 1978 has amply emphasized the availability and utilization of various health care equipment, at all levels, in the health system for effective and efficient service delivery. ${ }^{1,2}$

Medical equipment is used for the specific purposes of diagnosis and treatment of disease or rehabilitation following disease or injury and it can be used either alone or in combination with any accessory, consumable, or another piece of medical equipment. ${ }^{3}$ Medical equipment excludes implantable, disposable, or single-use medical devices. ${ }^{4}$ Dental institution and hospital equipment falls into an extremely wide spectrum ranging from a simple curing unit to complex one, such as VistaScan, Physiodispenser, and cone beam computed tomography (CBCT) scanner.

Equipment efficiency is one of the factors that are frequently overlooked by the management which can lead to losses by reducing yield. Inadequate preventive maintenance of equipment will result in low standards of diagnosis and treatment and increases the cost of maintenance of equipment. ${ }^{5-9}$ Utilization index is one of the important parameters to monitor the functional status of the equipment or it is the parameter to assess the productivity of service of equipment. An optimum utilization of the equipment will result in optimal patient handling and rapid turnover, minimum possible cost, quality patient care, and patient satisfaction. ${ }^{10-12}$ Hence, the study was conducted with objectives, to assess utilization coefficient (UC) of dental institution equipment along with their maintenance schedule to increase operational efficiency. 


\section{MATERIALS AND METHODS}

A cross-sectional study was conducted in 2015 at a dental institution of Bengaluru employing equipment utilization analysis. The study protocol was approved by the Institutional Review Board and Institutional Ethical Committee. A complete list of medical diagnostic equipment was prepared according to different functional areas/sections of the department. Retrospective data for the year 2014 to 2015 were utilized for the study. Utilization coefficients of medical diagnostic equipment were studied for 12 months.

Some of the factors affecting utilization of equipment are training of the staff, equipment installed on turnkey basis, preventive maintenance and after-sales services, facility for backup power supply, time scheduling of the hospital, awareness of the facilities, networking of special facility or skill, upgradeability, and the most important one is use coefficient. ${ }^{10,11,13}$

Use coefficient is applied to assess the utilization of equipment, i.e., whether the equipment is optimally utilized or underutilized. Use coefficient of equipment is measured by the following formula:

$$
\text { Use coefficient }=\frac{N}{M} \times 100
$$

where

$\mathrm{N}=$ Average number of hours the equipment is used per day.

$\mathrm{M}=$ Maximum number of hours the equipment can be used per day.

To assess the UC of these equipments, working hours of the dental institution was recorded. It was found that the daily work schedule of institution was 8:30 AM to 4:30 PM without any emergency shifts and 1 hour lunch time (1-2 PM). Saturday is half working day, i.e., 8:30 AM to 1:30 PM without any lunch break. Sundays and national holidays were excluded.

If the use coefficient is $<50 \%$, it is considered to be underutilized and hence a bad investment. However, lifesaving equipment cannot be subjected to this kind of assessment. ${ }^{14}$

Efficient equipment utilization should be ensured to optimize health care facilities. A substantial number of equipment in Indian health care institutions is of foreign origin. It is imperative that appropriate steps are taken in the planning, procurement, installation, and usage stages of these equipments to maximize utilization and optimize health care facilities.

Maintenance schedule of all the medical equipment available in dental institution was recorded as shown in Flow chart 1. Statistical analysis of the data was performed using the Microsoft Excel software.
Flow chart 1: Efficient equipment utilization - Planning, procurement, installation, and usage

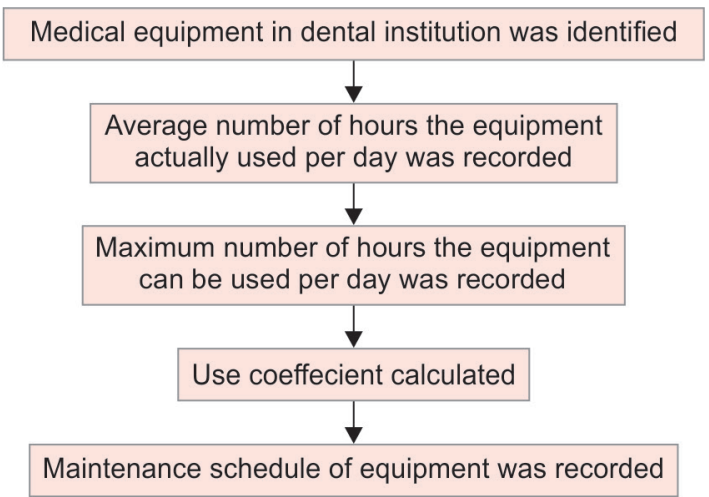

\section{RESULTS}

Actual number of hours for which equipment is used, maximum number of hours for which equipment can be used, along with this UC calculated for each equipment, is mentioned in Table 1. Casting furnace Dentsply has maximum use coefficient of $93 \%$, whereas casting furnace Magnaplus and automatic programmable vacuum porcelain furnace has UC of 33 and $67 \%$ respectively. The CBCT has UC of $64 \%$ and Unicorn DenMart has $57 \%$. UC laser surgical unit is underutilized as it has UC of $17 \%$. VistaScan installed in Endodontics Department has UC of $57 \%$, but the one present in Pedodontics Department has UC of 7\% (least among all equipment). In Table 2, all medical diagnostic equipment is ranked by their UC.

Maintenance contract availed by dental institution for various equipments is shown in Table 3. Out of 12 equipments, only four have preventive maintenance done thrice

Table 1: Utilization rate/UC of equipment

\begin{tabular}{|c|c|c|c|}
\hline Equipments & $\begin{array}{l}\text { Actual } \\
\text { number } \\
\text { of hours } \\
\text { used }\end{array}$ & $\begin{array}{l}\text { Maximum } \\
\text { number of } \\
\text { hours can } \\
\text { be used }\end{array}$ & $U C$ \\
\hline Carestream CS9300C CBCT & 4.5 & 7 & 64.29 \\
\hline Unicorn DenMart dental X-ray & 4 & 7 & 57.14 \\
\hline $\begin{array}{l}\text { Laser HF surgical unit serial no. } \\
0043\end{array}$ & 1 & 6 & 16.67 \\
\hline $\begin{array}{l}\text { VistaScan Mini Plus } \\
\text { C234969055 Durr Dental }\end{array}$ & 4 & 7 & 57.14 \\
\hline Seiler dental microscope & 2 & 7 & 28.57 \\
\hline $\begin{array}{l}\text { Semi-automatic microtome HM } \\
355\end{array}$ & 1 & 7 & 14.29 \\
\hline Calorimeter model 312 & 3.5 & 7 & 50.00 \\
\hline $\begin{array}{l}\text { VistaScan Mini Plus } \\
\text { B224702108 Durr Dental }\end{array}$ & 0.5 & 7 & 7.14 \\
\hline Physiodispenser implant & 0.5 & 4 & 12.5 \\
\hline $\begin{array}{l}\text { Casting furnace Dentsply } \\
\text { Multimat } 2\end{array}$ & 6.5 & 7 & 92.86 \\
\hline $\begin{array}{l}\text { Casting furnace Magnaplus } \\
\text { D200 }\end{array}$ & 2 & 6 & 33.33 \\
\hline $\begin{array}{l}\text { Automatic programmable } \\
\text { vacuum porcelain furnace }\end{array}$ & 4 & 6 & 66.67 \\
\hline
\end{tabular}


Table 2: Ranked list of medical equipment by their utilization coefficient

\begin{tabular}{llll}
\hline Equipment & UC & $\begin{array}{l}\text { Rank on the basis of } \\
\text { percentage utilization }\end{array}$ & $\begin{array}{l}\text { Investment on the medical } \\
\text { diagnostic equipment }\end{array}$ \\
\hline Casting furnace Dentsply Multimat 2 & 92.86 & 1 & Good \\
Automatic programmable vacuum porcelain furnace & 66.67 & 2 & Good \\
Carestream CS9300C CBCT & 64.29 & 3 & Good \\
Unicorn DenMart dental X-ray & 57.14 & 4 & Good \\
VistaScan Mini Plus C234969055 Durr Dental & 57.14 & 5 & Good \\
Calorimeter model 312 & 50.00 & 6 & Not good \\
Casting furnace Magnaplus D200 & 33.33 & 7 & Not good \\
Seiler dental microscope & 28.57 & 8 & Not good \\
Laser HF surgical unit serial no. 0043 & 16.67 & 9 & Not good \\
Semi-automatic microtome HM 355 & 14.29 & 10 & Not good \\
Physiodispenser implant & 12.5 & 11 & Not good \\
VistaScan Mini Plus B224702108 Durr Dental & 7.14 & 12 &
\end{tabular}

Table 3: Maintenance schedule of equipment available in dental institution

\begin{tabular}{lll}
\hline Equipment & Maintenance contract & Maintenance schedule \\
\hline Carestream CS9300C CBCT & $\mathrm{CMC}$ & Preventive maintenance (thrice per year) \\
Unicorn DenMart dental X-ray & $\mathrm{AMC}$ & Preventive maintenance (thrice per year) \\
Laser HF surgical unit serial no. 0043 & $\mathrm{Nil}$ & Breakdown maintenance \\
VistaScan Mini Plus C234969055 Durr Dental & $\mathrm{Nil}$ & Breakdown maintenance \\
Seiler dental microscope & $\mathrm{Nil}$ & Breakdown maintenance \\
Semi-automatic microtome HM 355 & $\mathrm{Nil}$ & Breakdown maintenance \\
Calorimeter model 312 & $\mathrm{Nil}$ & Breakdown maintenance \\
VistaScan Mini Plus B224702108 Durr Dental & $\mathrm{Nil}$ & Breakdown maintenance \\
Physiodispenser implant & $\mathrm{Nil}$ & Preventive maintenance (thrice per year) \\
Casting furnace Dentsply Multimat 2 & $\mathrm{Nil}$ & Preventive maintenance (thrice per year) \\
Casting furnace Magnaplus D200 & $\mathrm{Nil}$ & Breakdown maintenance \\
Automatic programmable vacuum porcelain furnace & $\mathrm{Nil}$ & Breakdown maintenance \\
\hline
\end{tabular}

per year, whereas for other eight equipments, breakdown maintenance is provided.

\section{DISCUSSION}

This study was conducted in a dental institution with more than 250 dental chairs, situated in Bengaluru, Karnataka, India. The range of services offered includes oral medicine and radiology, implantology, endodontics, pedodontics and preventive dentistry, etc., and different equipment is used to deliver various preventive, diagnostic, therapeutic, supportive, and control procedures for daily patient care activities. A total of 12 medical equipments were studied for their UC and maintenance schedule which are listed in Table 1. According to Table 1, only equipment reported to have use coefficient above $90 \%$ was casting furnace Dentsply Multimat 2. And casting furnace Magnaplus D200 and automatic programmable vacuum porcelain furnace have use coefficient of 33 and $67 \%$ respectively, and both these furnaces are used for the preparation of ceramic and metal ceramic crowns. To increase the utilization efficiency, institution can have tie up with local dentists for providing such crowns on request.
The UC of CBCT and intraoperative periapical machine was reported between 55 and $65 \%$, which represents good utilization and can be regarded as good investment. To ensure optimum utilization of CBCT, a marketing strategy can be developed where services can be made known to the community to gain maximum benefit of the capital invested. Networking with other hospitals and dental institutions would also ensure optimum utilization of the CBCT.

Institution has two VistaScan equipment to take X-ray, one in Department of Endodontics and another one in Pedodontics, which have use coefficient of 57.14 and $7.14 \%$ respectively. Having use coefficient $7.14 \%$ $(<50 \%)$, it is considered to be underutilized and hence a bad investment. To ensure its optimum utilization, both the departments can share one VistaScan equipment. It will help in reducing indirect cost, such as maintenance cost, electricity, and space cost.

Laser high frequency (HF) surgical unit used for periodontal surgical procedures has use coefficient of $17 \%$ and Physiodispenser used for placing dental implants has use coefficient of $12.5 \%$. It means both the equipments are bad investment as they are underutilized. As both the equipments are based on advanced technology, 
networking with other hospitals and dental institutions would help in optimum utilization. And also a marketing strategy can be developed where services can be made known to the community to gain maximum benefit of the capital invested.

Medical equipment must be maintained in working order and periodically calibrated for effectiveness and accuracy of the results. ${ }^{15-19}$ While purchasing medical equipment, the manufacturer company provides the service through annual maintenance contract (AMC) or comprehensive maintenance contract (CMC) by themselves or with the help of service providers. Planned preventive maintenance involves maintenance performed to extend the life of the equipment and prevent its failure and breakdown maintenance is performed to identify, isolate, and rectify a fault so that the out of order equipment, machine, or system can be restored to an operational condition. ${ }^{15}$ Maintenance schedule followed for different equipment is shown in Table 3.

Any electronic product requires timely service to function properly. In hospitals, there is always a danger of undesirable machine breakdown. Insisting on regular aftersales services of the equipment and a proper system of preventive maintenance, downtime of costly and essential equipment can be considerably reduced, thereby increasing utilization. Preventive maintenance can save a lot of time and money. Normally the annual maintenance cost of equipment varies from 1 to $4 \%$ of the capital cost of the equipment. With the help of preventive maintenance services, it is possible to predict and identify parts which are at verge of collapse. By ensuring availability of repairs, maintenance, and necessary spares, equipment utilization can be significantly increased.

To provide the best health care services, there is a need of the best quality medical equipment which helps in diagnosis, treatment, and monitoring of patients (staff and beneficiaries). Some of the equipment is also to be used for teaching and research purpose. Guidelines framed should be followed to keep this equipment well maintained to get the accurate results to provide the best health care services to staff and beneficiaries.

Inadequate maintenance schedule, restricted availability, lack of awareness, and low affordability were thought to be the factors responsible for poor equipment utilization. Further study needs to be conducted to assess the factors responsible for underutilization of these equipments.

\section{RECOMMENDATIONS}

Strategic planning has to be done by all the dental institutions to manage medical equipment and embrace a proactive role in the procurement of right medical equipment at the right working place and at the right time with right maintenance contract. Periodic equipment auditing needs to be practiced along with evaluation of the quality of performance of equipment in the dental institution.

To increase the utilization of equipment, institutions can have tie up with local dentists to provide porcelain crowns on request. Marketing strategy can be adopted where networking with other hospitals and dental institutions would ensure optimum utilization of the CBCT, Physiodispenser, and periodontal surgical laser unit. The quality of care can be significantly increased by availing AMC or CMC, which will ensure availability of repairs, maintenance, and necessary spares at periodic intervals. Care must be taken at the time of procurement that there must be a provision for the upgradation of technology after some years of use of that equipment.

\section{CONCLUSION}

Around $50 \%$ of medical equipment under study in the dental institution was used adequately (with UC around $50 \%$ ). Moreover, only $33 \%$ of medical equipment had regular preventive maintenance. In an era of costintensive medical care, every equipment being installed in health care institutions need to be fully and properly utilized. We believe our analysis will serve as a useful reference to all concerned namely academic institutions, dental administrators, practitioners, government, and management in optimizing equipment utilization to increase operational efficiency.

\section{REFERENCES}

1. Lathwal OP, Banerjee A. Availability and utilization of major equipments at district hospital Gurgaon, Haryana. J Acad Hosp Adm 2001;13(2):23-28.

2. Chaudhary P, Kaul P. An assessment of diagnostic equipment utilization in a tertiary healthcare setup: a key to economical patient management. Int J Res Found Hosp Healthc Adm 2014 Jul-Dec;2(2):111-116.

3. World Health Organization. Medical device technical series: introduction to medical equipment inventory management. Geneva, Switzerland: WHO Press; 2011. p. 1-31.

4. Chaudhary P, Kaul P. Factors affecting utilization of medical diagnostic equipment: a study at a tertiary healthcare setup of Chandigarh. CHRISMED J Health Res 2015 Sep;2(4):316-323.

5. Subramaniam SK, Husin SH, Yusop Y, Hamidon AH. Machine efficiency and man power utilization on production lines. Proceedings of the 8th WSEAS international conference on electronics, hardware, wireless and optical communications; 2009 Feb 21-23, Cambridge. 2009. p. 70-75.

6. IGNOU, School of Health Sciences. Introduction to management II: practical manual. New Delhi: IGNOU; 2011. p. 40-49.

7. Thukral R, Kumar A, Prasant MC, Punjabi KM, Paliwal A, Patel K. Assessment of patients referred to specialty dental hospitals for dental implant procedure: a retrospective cohort analysis. J Contemp Dent Pract 2016 Jun;17(6):470-475. 
8. Peck MT, Chrcanovic BR. Chemical and topographic analysis of eight commercially available dental implants. J Contemp Dent Pract 2016 May;17(5):354-360.

9. Jalali H, Bahrani Z, Zeighami S. Effect of repeated firings on microtensile bond strength of bi-layered lithium disilicate ceramics (e.max CAD and e.max Press). J Contemp Dent Pract 2016 Jul;17(7):530-535.

10. IGNOU, School of Health Sciences. Introduction to management II: essentials of logistics and equipment management. New Delhi: IGNOU; 2010. p. 45.

11. Gupta S, Kant S. Hospital stores management an integrated approach. 1st ed. New Delhi: Jaypee Brothers; 2000. p. 134-135.

12. Hospital Equipment Utilization: Increasing Operational Efficiency; 2008. Available from: http://www.medicalbuyer. co.in/index.php?option $=$ com_content\&task=view\&id=573.

13. Gupta SK, Kant S. Equipment audit-sine qua non for optimum utilization and efficiency; 2008. Available from: http://www.medicalbuyer.co.in/index.php?option=com content\&task=view\&id=596.
14. Kumar PN. Utilization study of CT scan in a multi-specialty hospital. Int J Sci Res 2014 Jul;3(7):1-2.

15. Employee's State Insurance Corporation. Medical equipment maintenance policy, 2012. New Delhi: Employee's State Insurance Corporation; 2012. p. 2-19.

16. Joshi D, Joshi M. Hospital administration. 1st ed. New Delhi: Jaypee Brothers Medical Publishers; 2009. p. 352.

17. Ibiapina DJ, Oltramari-Navarro PV, Navarro RL, Almeida MR, Mendonça DL, Conti AC. Assessment of dental arch changes and buccal bone thickness in patients treated with selfligating brackets. J Contemp Dent Pract 2016 Jun;17(6): 434-439.

18. Anand P, Anand PB, Prabhakar R, Rajvikram N, Rajakumar P, Atali VR, Saravanan R. Immediate and delayed effects of diode laser on debonding of ceramic brackets: an in vitro study. J Contemp Dent Pract 2016 Apr;17(4):275-281.

19. Maroua AL, Ajaj M, Hajeer MY. The accuracy and reproducibility of linear measurements made on CBCT-derived digital models. J Contemp Dent Pract 2016 Apr;17(4):294-299. 